\section{Infradiane Rhythmen}

Helga Peter ${ }^{1}$ und Thomas Penzel ${ }^{2}$

${ }^{1}$ Marburg, Deutschland

${ }^{2}$ Interdisziplinäres Schlafmedizinisches Zentrum, Charité -

Universitätsmedizin Berlin, Berlin, Deutschland

\section{Englischer Begriff}

infradian rhythms

\section{Definition}

Rhythmische Veränderungen mit einer Periodendauer von mehr als 24 Stunden. Ein Beispiel hierfür ist der Menstruationszyklus. 